\title{
Chapter 24 \\ Arctic Tourism: The Design Approach with Reference to the Russian North
}

\author{
Svetlana Usenyuk and Maria Gostyaeva
}

\begin{abstract}
This chapter discusses the potential of design research and education practice to contribute to Polar/Arctic tourism studies. With the geographical reference to the Russian Far North, it is explored what involves in being a human in severe environmental conditions, and what kind of design, clothing, dwelling, transportation it fosters. As a key argument, a perspective is developing of the arctic tourism as an embodied way of (short-term) living in the extreme environment. The discussion is continued by outlining the design approach to Arctic tourism development and based on existing variety of tourism resources in the Russian North two modes of their representation by design - static and dynamic - are suggested. Each mode is further illustrated with a case study of design projects conducted at the Arctic Design School, Yekaterinburg, Russia. To conclude, this chapter offers new ways of understanding and using design as a tool to respond to challenges and opportunities that today's Arctic uncovers not only for tourism, but also for other sectors of Arctic-based and oriented industry.
\end{abstract}

\subsection{Introduction}

Today, the tourism industry is one of the most prominent sectors of economy for many countries and communities worldwide. In the Arctic region, ${ }^{1}$ despite of its remoteness and strong seasonality as well as the historical dominance of intensive resource exploitation, such as mining, fishing, and oil \& gas extraction (Duhaime and Caron 2006; Brigham 2007), the tourism industry shows consistent growth in terms of the quantity of tourists and the portion of income (Maher et al. 2014). However, in Russia, which possesses almost 2/3 of the Arctic territory, the

\footnotetext{
${ }^{1}$ For the purpose of this chapter, the Arctic is defined as in the first Arctic Human Development Report (2004, pp. 17-18), with addition of the middle part of Western Siberia, i.e. Khanty-Mansy autonomous okrug, based on the specific definition of the Russian Far North given by Soviet geographer S.V. Slavin (1972).

S. Usenyuk • M. Gostyaeva $(\square)$

Ural State University of Architecture and Art, Yekaterinburg, Russia

e-mail: maria_gostyaeva@mail.ru
} 
development of Arctic-based tourism is a new issue in the public strategic planning, research and commercial activities (Kharlampieva 2016).

In this article, the design exploration starts with a statement that the Russian Far North has potential to become a platform for diverse tourism development and, furthermore, to enable new kinds of tourist products and services. Design as a system of material objects and actions aimed at changing existing situations into preferred ones (Simon 1996), can support this trend and provide for embodying new standards of tourism ethics and sustainability in the Arctic region. This article contributes to the studies of Arctic tourism development by changing the perspective on tourism and illuminating new opportunities for transforming given resources into tourist products/services by design.

This study relies on the experience of the Arctic Design School, ADS (Ural State University of Architecture and Art, Yekaterinburg, Russia) obtained during over 30 years of studio and field-based research, teaching and designing for the extreme environment of the Arctic. By focusing on adaptation and sustainability, it is suggested here to consider remote terrains of the Russian Far North as a natural 'living lab' (Bergvall-Kareborn et al. 2009), which provides an exceptional window to what is involved in being a human in severe conditions, and to what innovative design solutions it fosters.

The next paragraph outlines the theoretical foundation for design in Arctic tourism and later on two case studies from collective projects at the ADS are used to illustrate the theoretical background.

\subsubsection{Theoretical Foundation for Design in Tourism}

Known as one of the greatest producers of experiences (Binkhorst and Dekker 2009), tourism industry constantly calls for efficient 'mechanism' of transforming natural attractions into meaningful memorable experiences of users/tourists. On the other hand, design broadly defined as a field of theory and practice of developing products, services, processes, events, and environments, and particularly its subfield so-called 'experience design' is a unique professional activity with predominant focus on the quality of the human/user experiences. More precisely, the focus of experience design is on creating new experiences through a deliberate construction of the service circumstances to deepen the engagement and emotional links with users (Shedroff 2001; Pullman and Gross 2004). Metaphorically speaking, designer is a "teller of materially expressed stories" (Usenyuk 2008). Linking this quality with the industry for producing and consuming stories, tales and experiences, gave rise to a new professional field, i.e. "tourism experience design" (a concept formulated by Tussyadiah 2014).

With regard to the research and educational practice of the ADS, the concept of experience design fits perfectly to describe the main approach in tourism-oriented 
projects. Drawing on key theoretical foundations that frame the practice of experience design in tourism, such as human-centeredness, iterative designing process, and a holistic experience concept (Tussyadiah 2014), the ADS developed its own design approach to the Arctic tourism development based on three key points:

- Safety/adaptation: this point is rooted in general human-centeredness of design, with a particular aim to introduce users to a new/extreme environment and new culture gently, as well as to keep them unharmed ${ }^{2}$ and healthy during and - as long as possible - after the trip;

- Interactivity: this point implies tangible interactions (between tourists and objects that constitute the physical environment of the tourist trip, i.e. special clothing and equipment, transport vehicles, dwelling units), social interactions (between tourists and local communities), and post-trip interactions (between tourists and objects associated with the destinations, i.e. souvenirs);

- Sustainability: this point stems from the very mission of ADS, i.e. understanding of and integrating local/indigenous knowledge into the design process, and implies using tourism as a tool "to protect the natural and social capital upon which the industry is built" (McCool and Moisey 2008) and "maintain the Arctic as a desirable place to live" (Miettinen 2012).

Today, across the vast territory of the Russian North, there is a substantial imbalance between what the territory can provide and the tourism industry can utilize. As Maher et al. (2014) observe, local tourism offerings do not vary considerably and are primarily constituted of "hunting and fishing trips, ethnographic tours based on the traditions and culture of the indigenous people of the area, adventure tourism (including snowmobile safaris, white-water rafting, hiking and trekking)".

To rebalance the existing asymmetry between the content of tourism offerings and actual tourism resources of the Russian North, two modes of transforming resources into genuine tourist experiences with the aid of design - static and dynamic - are suggested here (Table 24.1) (terms by Usenyuk 2008).

In the following section, each mode is illustrated by exploring two connected cases: firstly, through a project developing a 'static' museum complex; secondly, through a project creating 'dynamic' lifetime experience in an extreme authentic location. Implications for Arctic tourism principles and practices arising from the presented design approach are discussed after that.

\footnotetext{
${ }^{2}$ In case of the location, physical safety is critical, as Maher et al. (2014) mention the system of emergency rescue as one of the main issues of the tourism industry in the Russian North: it is "yet to be developed and along with the rather specific Russian safety standards (drinking while driving, skepticism towards use of the safety equipment) adds to the uncertainty surrounding tourists' safety in the Arctic."
} 
Table 24.1 Two modes of transforming tourist resources into tourist experiences

\begin{tabular}{l|l|l}
\hline Core idea & Static & Dynamic \\
\hline Core experience & Tights are delivered to a tourist & A tourist is delivered to sights \\
\hline $\begin{array}{l}\text { Tourism touch } \\
\text { points }\end{array}$ & $\begin{array}{l}\text { Places of deliberate / artificial } \\
\text { concentration of tourist value, which are } \\
\text { organized in easily accessible areas }\end{array}$ & $\begin{array}{l}\text { To experience the Arctic/North } \\
\text { proximally, face-to-face }\end{array}$ \\
\hline $\begin{array}{l}\text { Forms of } \\
\text { of tourist value, which are } \\
\text { difficult to access }\end{array}$ \\
\hline $\begin{array}{l}\text { Main task for } \\
\text { designers }\end{array}$ & $\begin{array}{l}\text { Museums, exhibitions, theme parks } \\
\text { developing an atmosphere provoking } \\
\text { tourists into feeling/learning/acquiring } \\
\text { new skills, etc. }\end{array}$ & $\begin{array}{l}\text { Guided tours, adventurous } \\
\text { safaris, long-term excursions, } \\
\text { expeditions, etc. }\end{array}$ \\
\hline
\end{tabular}

\subsection{Case Studies}

\subsubsection{Case Study 1: The Mammoth Museum in Lugovskoye Area}

The first case was a commissioned design project conducted by the group of designers from the ASD together with researchers from the Ethnographic Bureau, Ekaterinburg. The client was the administration of the State Museum of Man and Nature from the city of Khanty-Mansyisk.

The project took place at the Lugovskoye area in Khanty-Mansi Autonomous Okrug, i.e. marshy lowland filled with ancient bones of mammoths. ${ }^{3}$ In summer 2007, the Lugovskoye site became a place of creative collaboration between designers and historians and archaeologists working on an ambitious project aimed at developing a fundamentally new organizational and visual concept for a "museum in Western Siberia."

A detailed analysis of the situation revealed the distinctive value of both the geographic location and the nature of the resource: at that time (and until now), there were no museums established directly on sites of archeological excavations in Russia. Besides that, Lugovskoye is located next to the city of Khanty-Mansyisk, and a federal automobile road goes in close proximity. Thus, for the planned

\footnotetext{
${ }^{3}$ The timescale of the project: the excavations on site have been conducted over a number of years since 1998. In 2004 the Lugovskoye area was listed as one of the famous regional sights of exceptional historical and scientific value, and further declared as a natural historical monument on the international scale

The design stage began in 2007. After the successful presentation of the concept, the planning phase was scheduled for the next two years, but lately the whole project was cancelled due to the changed political and economic situation in the Okrug.
} 
museum complex the situation was uniquely arranged to combine natural concentration of tourist value with easy access. However, the value of the archaeological site "as such" was rather unclear for non-professionals and therefore was not enough to attract and satisfy a wide range of tourists. The key issue was the quality of tourist experience that the planned museum complex could provide - whether immersing into Siberian North in a virtual/remote and comfortable way could provide all or the most important of the experiences that visiting the Siberian wilderness in-person could. In this case, the added value was the opportunity to experience not just Siberian North but the North thousands years ago. To make this virtual leap into the distant history, the project team suggested two levels of further design development: organizational/intangible and material/tangible. The organizational level included development of specialized tourist services, ranging from short-term introductory excursions to participatory tours to the archaeological site. To ensure full immersion into the Ice Age, all the tours would include interactive programs to study paleontological findings and ancient technologies. Also, to maintain constant tourist interest to the location, the list of attractions would include: convenient and well-planned infrastructure (e.g. parking lots, public catering, facilities for entertainment and short-term stay, etc.); regularly updated educating and entertaining content of museum programs devoted to the history, biology, geology of the region, as well as to popularization of up-to-date scientific findings; and competitions and other events. Apart from that, the museum complex would include a Mammoth Institute with a permanent paleontological laboratory located on the territory of paleontological excavations, where in-house scientists and visiting researchers would work on collection and further processing of the field data year-round.

To reveal both the context and content of the unique location to users/visitors and to fulfill the above-mentioned organizational needs, the team developed a design concept with emphasis on its outstanding visual appearance, yet aimed to maintain the local nature and culture. While the predominantly flat landscape with the monotonous road leading at the future building did not allow for any dramatic/theatrical scenery, designers decided to put forward the building per se. The exterior of the museum was inspired by a bio-metaphor of a mammoth (Fig. 24.1). Several units divided spatially and functionally constitute an architectural entity by resembling the body of this prehistoric animal lying on its side. From the road, the building appears as a cross-section of permafrost: a massive glass wall with silhouettes of mammoths frozen into it. On the other side facing the direction of the forest, in the buildings resembling tusk fragments designers placed a hotel, observation areas and laboratories.

According to the feedback collected during the project's presentation at the State Museum of Man and Nature of Khanty-Mansyisk, the planned visual appearance of the museum complex, inspired by both the nature and mythology of the location, was equally welcomed by the locals (including indigenous communities) and potential tourists: while the former perceived the building as an organic part of the land but creatively updated, the latter ones noted its exotic but still recognizable look. 


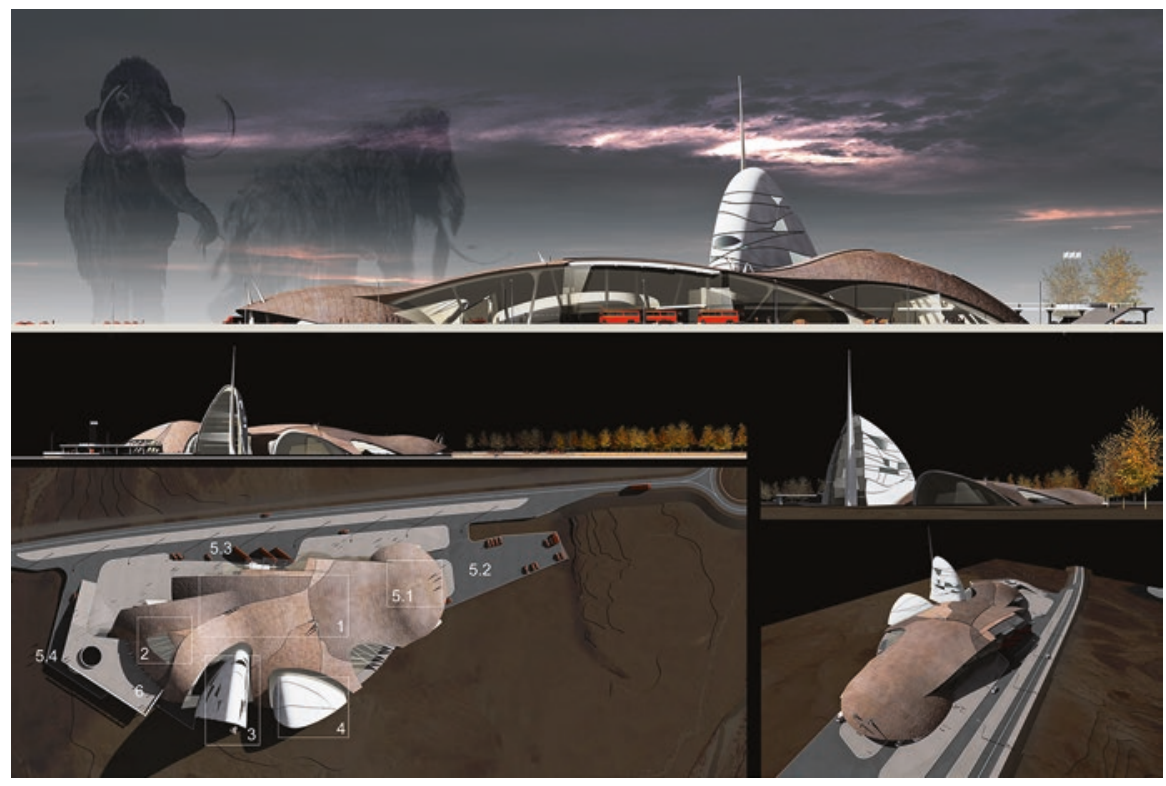

Fig. 24.1 The Mammoth Museum: visual presentation. Explanation of the numbers in the panel (bottom, left): 1 - exhibition unit; 2 - Mammoth Research Institute; 3 - hosting and catering facilities; 4 - paleontological research lab; 5.1-5.4 - parking lots (Courtesy of D. Kukanov)

This case illuminates the potential of design to augment the naturally given resources and deliver available attractions to tourists in a new - locally rooted, engaging and aesthetically touching - form.

\subsubsection{Case Study 2: The Tourist Complex in the Archipelago of Novaya Zemlya}

The second case was a master's degree project conducted by a group of seven students in 2012. This project illustrates the arctic application of the 'living lab' concept, described previously.

The archipelago of Novaya Zemlya, Arkhangelsk Oblast, was chosen as a location of the project aimed at developing a "tangible provocation" into a hypothetical model of comfortable human existence in the Far North (Fig. 24.2). The students used a figurative tourist complex as a 'living lab', i.e. a natural-social environment, in which the combination of environmental, social, economic and technological conditions provided for developing and testing objects, technologies and services to facilitate the physical, social and cultural adaptation of different groups of Arctic dwellers and visitors at a community level. To develop their visions of the modeled situation the students worked both in the studio and the field - not on the exact site, 


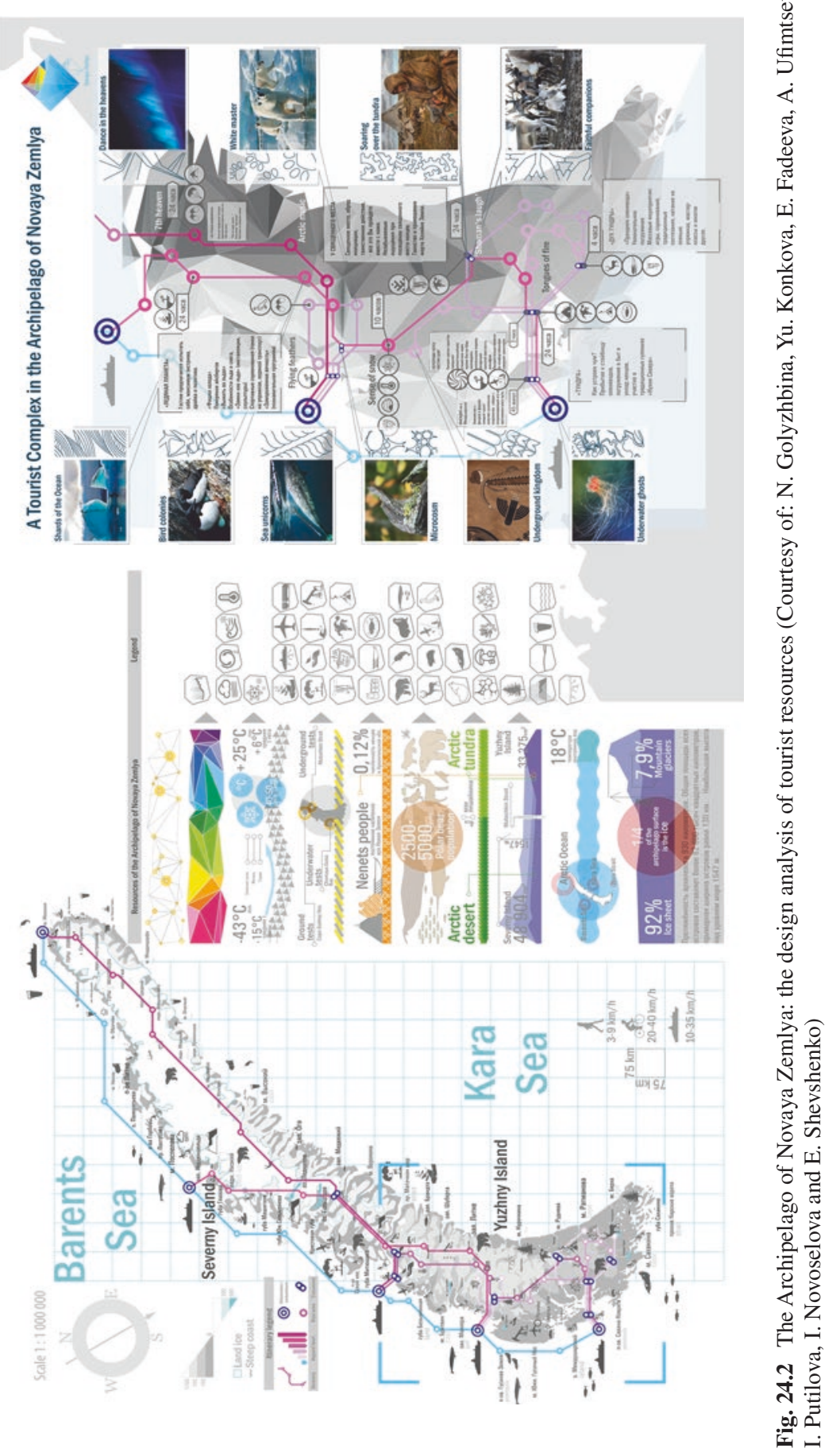


but in alternative locations in Northern and Polar Urals. They were also granted the access to the internal databases and collections of the Institute of History and Archaeology, the Ural branch of Russian Academy of Sciences. As a result, they came up with several design directions to follow:

- Image-making: an overall aesthetic appearance, which 'orchestrates' all tangible and intangible components of tourist safety and experience in the extreme environment;

- Storytelling: a gradually revealed process of producing and consuming tourist experiences;

- Material setting: a system of material objects based on local natural factors, which is used to coordinate a complex interplay between the extreme environment and human beings, i.e. to manage risks and diminish the overall extremity;

- Mobility: the combination of physical and mechanized movements, which plays the key role for human adaptation and survival by ensuring the proper functioning of the body. Transportation becomes a "smart carrier," i.e. a partner that not only carries people but also encourages them to switch to other kinds of movement, e.g. walking, running, etc. at various parts of the trip;

- Relaxation: a system of physio- and psychological adaptation as "software" that allows creating a unique and secure tourist experience. At the same time, the system of material objects serves as "hardware", i.e. intangible elements of the tourist complex that introduce the visitors to the extreme conditions.

The project yielded the following tangible outcomes (Fig. 24.3): a detailed scenario of events and actions/activities of a tourist during the trip; sets of personal equipment for the identified variety of tourist activities; a set of personal equipment for emergency rescue; a mobile dwelling unit; a chain of personal and communal transport vehicles that facilitates various kinds of tourist mobility; means of physical and psychological relaxation for extreme/adventurous tourist trips; a visual design concept of the tourist complex.

To conclude, in this case study the tourism application area gave rise to a radical revision of existing and development of fundamentally new methods for developing equipment, transport vehicles, housing, etc. The tourism framework revealed the potential of the modeled 'living lab' to co-develop and use a 'playful' system of safety equipment and services as essential elements of tourist experience during adventurous trips. In general, the field of Arctic tourism provided a prospective proving ground for solutions that might have further applications in space and other extreme and isolated environments. 

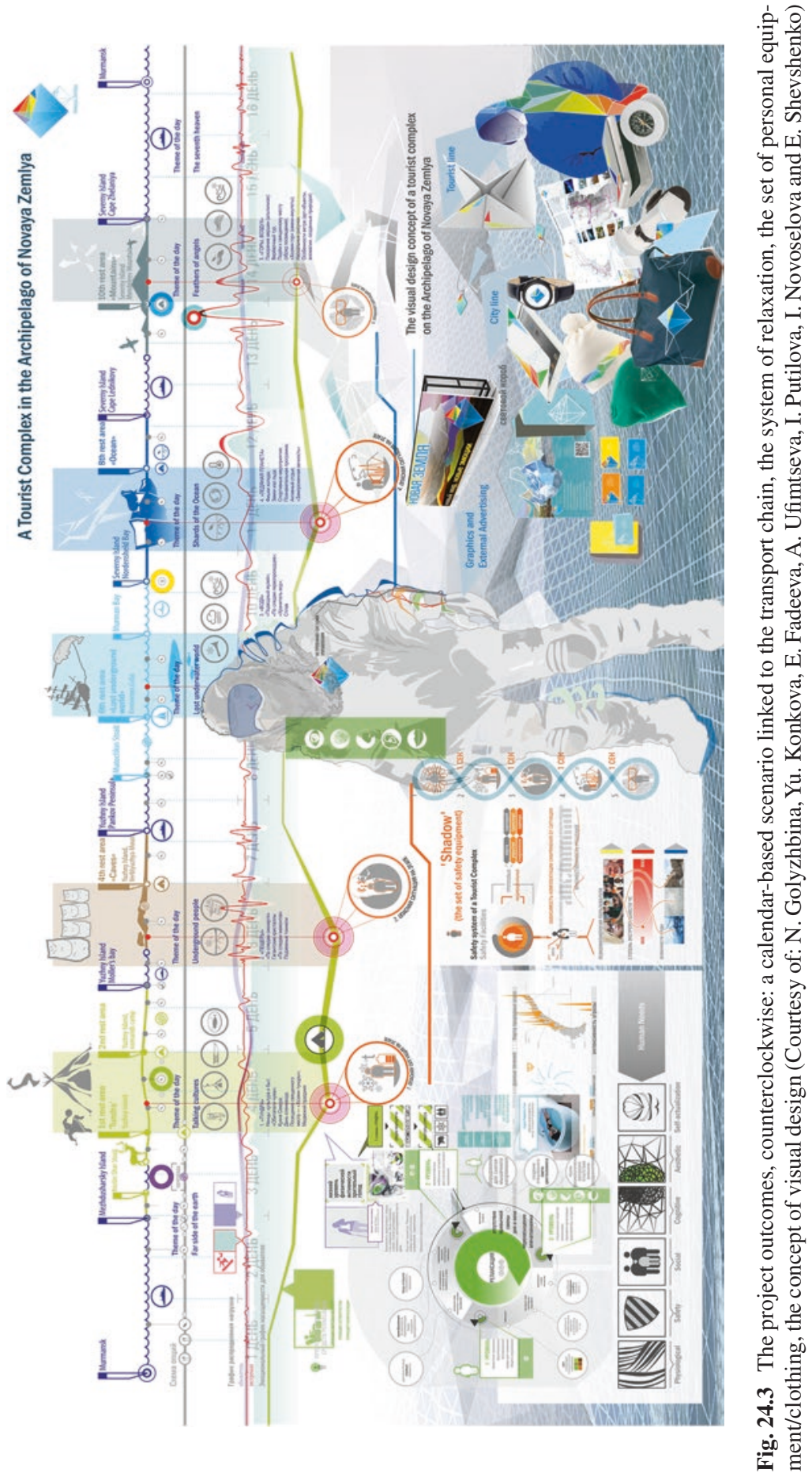


\subsection{Conclusions}

This chapter presents an innovative design approach - originated and tested at the Arctic Design School - for developing arctic tourism at the specific geographical and social-cultural setting of the Russian North.

The Arctic tourism framework inspired the designers of the approach to revisit their professional toolkit with the aim to develop, test and implement new ways of human comfortable living and working in the extreme environment. The 'living lab' approach presented in the second case study can potentially facilitate co-creation between designers and users/tourists as well as enable interaction among relevant Arctic stakeholders: in addition to tourism industry, those from extractive industries, military and a wide range of Arctic-related research and public organizations.

On the other hand, the design approach on the tourism principles and practices existing in the areas under study illuminated the opportunities of shifting the focus from tourism resources and destinations to human beings and their experiences acquired during the trip. The first case study illustrated the joint capacity of artistic imagination and organizational design in creation of genuine experience in a location with no previous tourism. While the focus on experiences is not a new approach in tourism in general, this chapter emphasizes its importance - and importance of human-centeredness - with regard to the tourism linked to locations with vulnerable nature and culture.

Also, the ideas and concepts presented in this chapter will be relevant for design and tourism educators involved in developing methodologies for collaborative research and teaching.

Overall, the chapter offers only a starting point for investigating the fruitful interplay between the tourism and design in the setting of Polar Regions.

\section{References}

Arctic Human Development Report (2004) Stefansson Arctic Institute, Akureyri

Bergvall-Kareborn B, Hoist M, Stahlbrost A (2009) Concept design with a living lab approach, in: System Sciences, 2009. HICSS'09. 42nd Hawaii International Conference on. IEEE, pp 1-10

Binkhorst E, Dekker TD (2009) Agenda for co-creation tourism experience research. J Hosp Mark Manag 18:311-327. doi:10.1080/19368620802594193

Brigham LW (2007) Thinking about the Arctic's Future. The Futurist 41(5):27-34

Duhaime G, Caron A (2006) The economy of the circumpolar Arctic. Econ North Oslo No Stat Nor 16-25

Kharlampieva N (2016) Theory and methodology of the Arctic tourism development. Arct North 23:124-129. doi:10.17238/issn2221-2698.2016.23.124

Maher PT, Gelter H, Hillmer-Pegram K, Hovgaard G, Hull J, Jóhannesson GT, Karlsdóttir A, Rantala O, Pashkevich A (2014) Arctic tourism: realities and possibilities. Arct Yearb 2014:290-306

McCool SF, Moisey RN (2008) Tourism, recreation, and sustainability: linking culture and the environment, 2nd edn. CABI, Wallingford/Cambridge, MA 
Miettinen S (2012) Service design, radical innovations and arctic wellbeing, in: arctic design opening the discussion. University of Lapland, pp 28-33

Pullman ME, Gross MA (2004) Ability of Experience Design Elements to Elicit Emotions and Loyalty Behaviors. Decis Sci 35:551-578. doi:10.1111/j.0011-7315.2004.02611.x

Shedroff N (2001) Experience design. New Riders, Indianapolis

Simon HA (1996) The sciences of the artificial, 3rd edn. MIT Press, Cambridge

Slavin SV (1972) Osnovnye voprosy povysheniya effektivnosti, razvitiya i razmescheniya proizvoditel'nykh sil Severa SSSR [Fundamental Issues of Increasing the Efficiency, Developing and Locating the Productive Forces of the USSR's North], in: Northern Issues [Problemy Severa]. Nauka, Moscow

Tussyadiah IP (2014) Toward a theoretical foundation for experience design in tourism. J Travel Res 53:543-564. doi: $10.1177 / 0047287513513172$

Usenyuk S (2008) The Russian North: Northern tourism through design professionals. Tour Hosp Plann Dev 5:131-147. doi:10.1080/14790530802252792

Open Access This chapter is licensed under the terms of the Creative Commons Attribution 4.0 International License (http://creativecommons.org/licenses/by/4.0/), which permits use, sharing, adaptation, distribution and reproduction in any medium or format, as long as you give appropriate credit to the original author(s) and the source, provide a link to the Creative Commons license and indicate if changes were made.

The images or other third party material in this chapter are included in the chapter's Creative Commons license, unless indicated otherwise in a credit line to the material. If material is not included in the chapter's Creative Commons license and your intended use is not permitted by statutory regulation or exceeds the permitted use, you will need to obtain permission directly from the copyright holder.

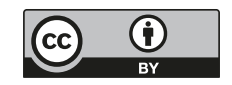

